Research Article

\title{
Diagnosis Index System Setup for Implementation Status Management in Large-Scale Construction Projects
}

\author{
Wan-Yu Wang $(\mathbb{D}$ and Yi Wang \\ School of Economy and Management, North China Electric Power University, Beijing 102206, China \\ Correspondence should be addressed to Wan-Yu Wang; wangwanyu@ncepu.edu.cn
}

Received 25 February 2021; Revised 8 May 2021; Accepted 27 May 2021; Published 10 June 2021

Academic Editor: Sudhakarapandian RanjithaRamasamy

Copyright (C) 2021 Wan-Yu Wang and Yi Wang. This is an open access article distributed under the Creative Commons Attribution License, which permits unrestricted use, distribution, and reproduction in any medium, provided the original work is properly cited.

\begin{abstract}
In order to scientifically set up the diagnosis index system for the implementation state of large-scale construction projects, this paper proposed a new method which takes into account the indicators in all level states. Different from the index system constructed by other methods, the indexes/indicators established in this paper are more systematically correlated, with a better hierarchical progression in all levels of the index system. The particular diagnosis index parameters of the management objects are firstly analysed through the mathematic model based on the Rough Set. Then, the representation of the periodical management problems is taken as the study object, and the detailed establishing process to form the index system is presented based on the evidenced theory and the Rough Set extraction. Finally, a case study is presented to validate the proposed method. It is shown that the index system set up by the proposed method can not only represent the systematic hierarchical relationships among all corresponding indexes but also diagnose the macroscopic, the mesostates, and the microstates effectively.
\end{abstract}

\section{Introduction}

The establishing method of the index system for the construction projects is essential to scientific management [1]. Previous studies have validated the significance of the proper index system for sustainability in the highway construction projects $[2,3]$, and for the comprehensive assessment in the cross-border power grid interconnection projects [4].

However, the current frame of the index system is far from qualified in engineering applications. It is found that the traditional plan-driven model sometimes is not the most appropriate approach to complex construction projects subject to successive changes, while more agile approaches might be more adequate [5]. For instance, the internal audit effectiveness measurement index system in architecture construction projects faces the problems of large losses and waste, ineffective audit rectification, and lagging audit innovation [6], while the gas pipeline projects follow the issue of energy security and the need to diversify suppliers [7]. The key reason is that the index system for different projects needs too many efforts to concretize and verify the indexes/ indicators. Consequently, how to scientifically pick the sensitive parameters to form the effective index system has become the key point.

The index parameters refer to many factors. Taking the modular integrated construction $(\mathrm{MiC})$ project as an example, Wuni et al. identified and evaluated 22 potential critical failure factors (CFFs) for such $\mathrm{MiC}$ projects [8]. In addition, these parameters and factors correspond to varied project index types with different highlights and targets. Most commonly, the factors refer to the costs and waste $[9,10]$, the risk and safety [11-17], the procedure delay [18-20], the decision-making [21], and so forth. People have tried various methods to select the proper parameters and indicators for different index systems. Typically, Elfahham employed Neural Networks, Linear Regression, and Autoregressive Time Series to obtain the Construction Cost Index [9], while Okudan et al. proposed a knowledge-based risk management tool for the construction projects by using the case-based reasoning method [12]. To reduce the risk, the BIM-integrated safety assessment is widely used at the design stage in building projects [13]. For the construction 
projects which need to deal with multisource information, such as the tunnel construction [14] and the subway construction [16], the analytic network process and the extension cloud models are frequently employed to assess the safety and the risk of the project.

The aforementioned research developed varied indicators to form the index system by multifarious methods and models. However, most of them primarily selected the most related indicators, while the correlation of these indicators in different level stages was not finely taken into account. It has been shown that the systematic and dynamics model which considers the factors that affect the behaviour of the study object will be more scientific to form the qualified index system [22].

In this paper, we proposed a new approach which takes into account the indicators in all level states to set up the diagnosis index system for the implementation status management in large-scale construction projects. Different from the index system constructed by other methods, the indexes/indicators established in this paper are more systematically correlated, with a better hierarchical progression in all levels of the index system. The remainder of this paper is constructed as follows: the methodology to determine the diagnosis indicators and to construct the index system is proposed in Section 2, while the case study and the validation of the established index system are presented in Section 3. Finally, the primary conclusions are drawn up in Section 4.

\section{Methodology}

2.1. Basic Method Theory. In order to realize the effective management of large-scale construction projects through the diagnosis system, how to ensure the scientificity as well as the systematicness and completeness of the diagnosis indicators in the system is the primary issue.

Currently, there are many methods to analyse and determine the diagnosis index parameters of the implementation state of a project from many sources, such as the expert experience method, the homologous reference method, and the Rough Set (RS) extraction method [23-25]. Among these methods, the RS extraction method is the most effective one in practice. This method generally relies on the evidence-based theory and begins with the relative representation analysis.

In our proposed approach, we primarily employ the Rough Set (RS) extraction method based on the evidencebased theory. The evidence-based theory is the most effective method to obtain the problem representation of the project implementation state [26]. It takes the actual environment and the practical data of the management object to obtain the information and complete the description of the management object. Therefore, it has become the most popular problem representation method.

The application of the aforementioned RS extraction method based on the evidence-based theory requests three work steps, as illustrated in Figure 1.

As shown in Figure 1, to construct the index system, the problem representation of the management object needs to be obtained firstly. Second, the characteristic parameters need to be obtained by analysing the problem representation. Third, the characteristic parameters need to be transformed into the corresponding diagnosis index. Based on these three steps, the index system can be constructed. Among the three steps, the second one is the most important. During this step, it determines the representation features from the core of the problem by removing the redundant information and then obtains the characteristic parameters.

2.2. Determination of Diagnosis Indicators. In order to obtain the problem representations of the management objects in the practical large-scale construction projects, we obtained 5,738 pieces of information that effectively reflected the problems at various stages of the project through a survey of 276 managers.

By analysing the information obtained, we found that there are 258 common and typical problem representations, which are of 20 categories in total. Among these representations, 17 are for the decision-making stage belonging to 3 categories, 66 are for the preparation stage referring to 5 categories, 143 are for the construction stage belonging to 8 categories, and the other 32 are for the completion stage referring to 4 categories. Taking the decision-making stage as an example, the representations and the referring categories are listed in Table 1.

When dealing with the specific problems, the simplified information needs to be determined according to the project management rules, and the mathematical model can be written as [27]

$$
\operatorname{RED}(R)=\operatorname{RED}(R-(r)),
$$

where $\{r\}$ is the redundant information of the problem representation, and the kernel set $\operatorname{CORD}(R)$ is the rest of $\{\mathrm{KX}\}$ after the reduction. All of the representations $x$ of the problems in all stages of the project $K$ should be equivalent to the original set $\{\mathrm{KX}\}$ in $R$ degree [28].

Assuming that $T$ is the feature set of $x$ element in $\{\mathrm{KX}\}, P$ is the parameter set corresponding to $T$, and $I$ is the mapping index set with the same set potential as $P$; then, according to the RS theory, the kernel formed after reduction can be expressed as

$$
\operatorname{CORD}(R)=\mathrm{KX}-\mathrm{Kr}
$$

where

$$
\operatorname{Kr} \notin I\{\operatorname{CORD}(R): \operatorname{CORD}(R) \in \operatorname{RED}(\mathrm{KX})\} .
$$

Since $\operatorname{CORD}(\mathrm{R}) \in R: \mathrm{RED}(\mathrm{KX})$, all the objects contained in $\operatorname{CORD}(R)$ are related [29], and there is

$$
\begin{aligned}
& \operatorname{CORD}(R) \in \operatorname{RED}\{(\mathrm{KX}) \subseteq \Lambda(\mathrm{KX})\}, \\
& (\mathrm{KT})_{R} \subseteq \operatorname{IND}\{\mathrm{CORD}(R) \subseteq \Lambda(\mathrm{KX})\}, \\
& (\mathrm{KP})_{R} \subseteq \operatorname{IND}\{(\mathrm{KT}) \subseteq \Lambda(\mathrm{KX})\} .
\end{aligned}
$$


According to the coprime mapping, the parameters and the indicators have the same set potential, and we have

$$
f: \operatorname{dom}(R) \longrightarrow{ }^{\text {injec }} \operatorname{ran}(R) \Rightarrow\{\mathrm{KP}\} \longrightarrow{ }^{{ }^{i n j e c}}\{\mathrm{KI}\},
$$

where $\mathrm{KX}, \mathrm{KT}$, and $\mathrm{KP}$ are problem-depend parameters and need to be specified and symbolized according to the detailed topics. These characteristic parameters can be extracted through the analysis of all problem representations in each stage of the system, and then the diagnosis indicators can be obtained to establish a complete index system. The key issue of the RS method is to obtain the problem representations.

To determine the diagnosis index after obtaining the problem representations of the management object, an analysis on the characteristic parameters of the problem representation is needed. Taking the decision-making stage $A$ as an example, the 17 representations of the 3 categories, namely, the project planning $\mathrm{AX} 1$, the feasibility study analysis $\mathrm{AX} 2$, and the decision-making approval $\mathrm{AX} 3$, have the relations as

$$
\begin{aligned}
\{\mathrm{AX}\} & \supseteq\{\mathrm{AX} 1, \mathrm{AX} 2, \mathrm{AX} 3\} \\
& =\left\{\cup A x_{i} \in \mathrm{AX},\left(x_{i}, i=1-17\right)\right\} \\
& =\{A 1, A 2, \cdots A 1\} .
\end{aligned}
$$

Based on the analysis on the problem representations, it is shown that the decision-maker's unawareness of the current status $(A 1)$, the developing tendency $(A 2)$, or the relative policy $(A 3)$ during the project planning stage will lead to the miss of the construction scale and investment intention (A4) and cause divergence and disputation (A5). Consequently, the inefficient project proposal $(A 6)$ and the delay of the approval to higher departments $(A 7)$ will be produced. Therefore, the primary problems focus on the project conception and the construction proposal. To solve these problems, it needs to carry out the subject indexing and the problem symbolizing, as shown in Table 2 .

Then, according to the RS method, the characteristic parameters in AX1 can be extracted, and meanwhile, the diagnosis indicators can be obtained. The whole process can be expressed as

$$
\begin{aligned}
& \{\mathrm{AX} 1\}=\left\{\cup A x_{i}\left(x_{i}: i=1-7\right)\right\}=\{A 1, A 2, \cdots, A 7\}, \\
& \operatorname{CORD}(\mathrm{AR}) \in \operatorname{RED}\left\{(\mathrm{AX} 1) \subseteq \Lambda\left(\cup A x_{i}\left(x_{i}: i=1-7\right)\right)\right\} .
\end{aligned}
$$

Specifically,

$$
\begin{aligned}
& \because \operatorname{CORD}(\mathrm{AR} 1) \in \operatorname{RED}\left\{\cup A x_{i}\left(x_{i}: i=1-3\right)\right\}, \operatorname{CORD}(\mathrm{AR} 2) \in \operatorname{RED}\left\{\cup A x_{i}\left(x_{i}: i=4-5\right)\right\}, \\
& \operatorname{CORD}(\mathrm{AR} 3) \in \operatorname{RED}\left\{\cup A x_{i}\left(x_{i}: i=6-7\right)\right\} \\
& \therefore \mathrm{CORD}(\mathrm{AR}) \supseteq \cup\{\operatorname{AR} 1, \mathrm{AR} 2, \mathrm{AR} 3\},(\mathrm{AT} 111)_{R} \subseteq \operatorname{IND}\{\mathrm{CORD}(\mathrm{AR} 1) \subseteq \Lambda(\mathrm{AX} 1)\}, \\
& \quad(\mathrm{AT} 112)_{R} \subseteq \operatorname{IND}\{\mathrm{CORD}(\mathrm{AR} 2) \subseteq \Lambda(\mathrm{AX} 1)\},(\mathrm{AT} 121)_{R} \subseteq \operatorname{IND}\{\mathrm{CORD}(\mathrm{AR} 3) \subseteq \Lambda(\mathrm{AX} 1)\}, \\
& \quad(\mathrm{AT} 11)_{R} \supseteq \cup\{\mathrm{AT} 111, \mathrm{AT} 112\},(\mathrm{AT} 12)_{R} \supseteq \cup\{\mathrm{AT} 121\},(\mathrm{AT})_{R} \supseteq\{\mathrm{AT} 11, \mathrm{AT} 12\} \subseteq \Lambda(\mathrm{AX} 1) \\
& \quad \because(\mathrm{AP})_{R} \subseteq \operatorname{IND}\{(\mathrm{AT}) \subseteq \Lambda(\mathrm{AX})\} \\
& \therefore(\mathrm{AP} 111)_{R} \subseteq \operatorname{IND}\{\mathrm{AT} 111 \subseteq \Lambda(\mathrm{AX} 1)\},(\mathrm{AP} 112)_{R} \subseteq\{(\mathrm{ATT} 112) \subseteq \Lambda(\mathrm{AX} 1)\} \\
& \quad(\mathrm{AP} 121)_{R} \subseteq \operatorname{IND}\{(\mathrm{AT} 121) \subseteq \Lambda(\mathrm{AX} 1)\},(\mathrm{AP})_{R} \supseteq \cup\{\mathrm{AP} 111, \mathrm{AP} 112, \mathrm{AP} 121\} .
\end{aligned}
$$

Further, based on the same set potential of the parameters and the indicators, there is

$$
\begin{aligned}
& f: \operatorname{dom}(\mathrm{AR}) \stackrel{\text { injec }}{\longrightarrow} \operatorname{ran}(\mathrm{AR}) \Rightarrow\{\mathrm{AP}\} \stackrel{\text { injec }}{\longrightarrow}\{\mathrm{AI}\}, \\
& \because(\mathrm{AP})_{R} \supseteq \mathrm{U}\{\mathrm{AP} 111, \mathrm{AP} 112, \mathrm{AP} 121\}, \\
& \therefore\{\mathrm{AI}\}_{R} \supseteq \mathrm{U}\{\mathrm{AI} 111, \mathrm{AI} 112, \mathrm{AI} 121\} .
\end{aligned}
$$

Then, the diagnosis indicators of the management objects at all levels in the project planning stage are obtained. Similarly, the diagnosis indicators for the feasibility study stage and the decision approval stage can be determined as well; more details are shown in Table 3.
By employing the aforementioned method, the diagnostic indicators of the management objects at various levels in other stages of large construction projects can be also obtained. Limited by space, this paper mainly focuses on the establishing method of the problem indicators, while the detailed processes which can be found in [30] are not presented.

2.3. Construction of Index System. As previously analysed, since the diagnosis indicators that are proposed based on the RS theory are particularly aiming at the problem representations, they are the most direct indexes to diagnose the practical problems in construction projects. 


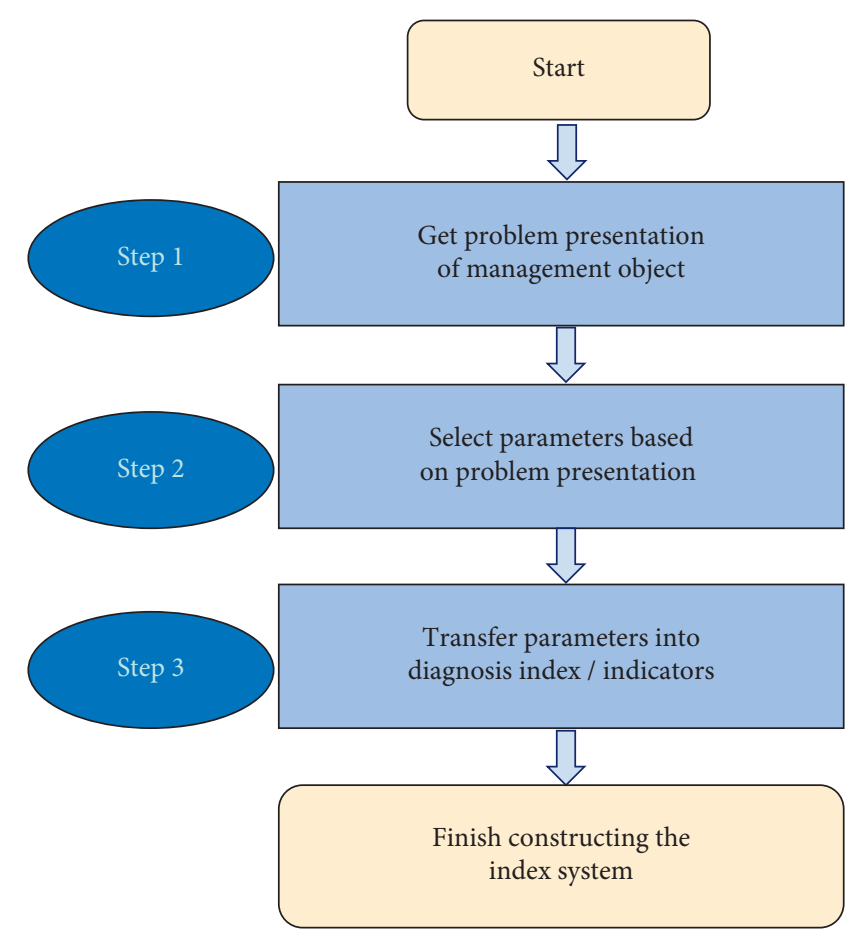

FIgURE 1: Index system construction steps.

TABle 1: Problem representations in decision-making stage.

\begin{tabular}{|c|c|c|}
\hline Category & Problem representation & Problem symbolization \\
\hline \multirow{7}{*}{ Project planning } & Current status unknown & $A 1$ \\
\hline & Developing trend unknown & $A 2$ \\
\hline & Policies not grasped & $A 3$ \\
\hline & Project positioning unclear & $A 4$ \\
\hline & Project decisions controversial & $A 5$ \\
\hline & Report inefficiently prepared & A6 \\
\hline & Report delayed & A7 \\
\hline \multirow{5}{*}{ Feasibility analysis } & Survey not actually performed & $A 8$ \\
\hline & Survey scope incomprehensive & $A 9$ \\
\hline & Information not true & $A 10$ \\
\hline & Method incorrect & $A 11$ \\
\hline & Content not comprehensive & $A 12$ \\
\hline \multirow{5}{*}{ Decisions and approvals } & Decision reference not reliable & $A 13$ \\
\hline & Decision process incorrect & $A 14$ \\
\hline & Decision-making inefficient & $A 15$ \\
\hline & Approval process not standard & $A 16$ \\
\hline & Approval inefficient & $A 17$ \\
\hline
\end{tabular}

Specifically, the indicators have the relationships as

$$
\begin{aligned}
(\mathrm{AI} 111 \cup \mathrm{AI} 112) & \in \mathrm{AI} 11, \\
(\mathrm{AI} 121) & \in \mathrm{AI} 12, \\
(\mathrm{AI} 11 \cup \mathrm{AI} 12) & \in \mathrm{AI} 1 .
\end{aligned}
$$

According to the above formulas, AI11 can be derived through AI11 and AI12, while AI12 can be inferred from AI121, and AI1 and be derived through AI11 and AI12. Similarly, AI21, AI22, and AI2 can be derived through AI121, AI211, AI212, AI213, AI221, and AI222, while AI31,
AI32, and AI3 can be inferred from AI311, AI321, and AI322.

Further, the overall situation of the project in the decision-making stage can be obtained through the derivation of AI1, AI2, and AI3. And the manager is able to obtain the systematic analysis and assessment on the managing objects in the decision-making stage from the microlayer to the macrolayer.

By using the same method, the indicators as well as their membership function in the preparation stage, the construction stage, and the completion stage can be derived, 
TABLE 2: Subject indexing and representation symbols.

\begin{tabular}{lcccc}
\hline $\begin{array}{l}\text { Category and } \\
\text { indexing }\end{array}$ & $\begin{array}{c}\text { Feature and } \\
\text { indexing }\end{array}$ & $\begin{array}{c}\text { Problem representation } \\
\text { indexing }\end{array}$ & $\begin{array}{c}\text { Representation features and } \\
\text { indexing }\end{array}$ & $\begin{array}{c}\text { Characteristic parameters and } \\
\text { indexing }\end{array}$ \\
\hline & & $A 1$ & & \\
& & $A 2$ & Incomplete information AT111 & Request information AP111 \\
Plan project AX1 & Project idea AT11 & $A 3$ & Imperfection of planning & Plan and analysis AP112 \\
& & $A 4$ & AT112 & Work efficiency AP121 \\
& Submit advice & $A 5$ & Inefficient report AT121 & AT12 \\
& $A 6$ & $A 7$ &
\end{tabular}

Table 3: Diagnosis index of management objects in the decision-making stage.

\begin{tabular}{lr}
\hline Diagnosis index & Index code \\
\hline Project plan & AI1 \\
Feasibility analysis & AI2 \\
Decision approval & AI3 \\
Conception & AI11 \\
Proposal & AI12 \\
Condition & AI21 \\
Analysis & AI22 \\
Decision & AI31 \\
Approval & AI32 \\
Information acquire rate & AI111 \\
Analysis improving rate & AI112 \\
Work-effect ratio of report & AI121 \\
Reliability rate & AI211 \\
Satisfaction rate & AI212 \\
Work-effect ratio of report & AI213 \\
Correctness rate & AI221 \\
Comprehensive rate & AI222 \\
Work-effect ratio & AI311 \\
Disobeying rate & AI321 \\
Work-effect ratio & AI322 \\
\hline
\end{tabular}

respectively. Then, according to the system structure of the diagnosis index presented in the scientific theories, the general diagnosis index system for the implementation state of each management object can be set up both in micro- and macroaspects, as illustrated in Figure 2.

\section{Case Study and Validation}

3.1. Case Study. In order to verify the scientificity and the effectiveness of the index system constructed by the aforementioned method, the index system was applied to a construction project for the implementation state diagnosis. The decision-making stage was taken as the specific detection object. The required information of the related 11 microdiagnosis indicators was input into the system to obtain the diagnosis value $T N$. Then, the diagnosis values of the macro- and the mesomanagement objects were calculated as well.

Meanwhile, six senior engineers, who were in charge of the project and had more than 15 years' experience, were invited to evaluate the actual status of the management objects in macro-, meso-, and microaspects. Scores were given by these engineers with the same criterion of the index system. Then, the test $\mathrm{RN}$ value can be obtained after the normalized performance on the scores. Finally, the error rate VR between TN and RN can be calculated, as shown in Table 4.

As indicated in Table 4, the maximum value of $\mathrm{VR}$ of the microstate diagnosis result is $10.8 \%$, while the minimum value is $1.05 \%$. The maximum and the minimum VR values of the median state diagnosis results are $10.4 \%$ and $1.12 \%$, respectively. The maximum VR value of the macrostate diagnosis is $7.40 \%$, while the minimum value is $0.81 \%$.

Since the maximum allowable test deviation of the Chinese large-scale construction project implementation status diagnosis system is $\pm 15 \%$ [31], the macro- and mesoresults by the proposed diagnosis index system can fully meet the requirements. Consequently, the ongoing macro and mesostatus of the project can be reflected rapidly with a qualified accuracy.

\subsection{Discussion}

3.2.1. About Determination of Indicators. The established diagnosis index system, which has been applied in the practical construction projects, includes many kinds of diagnosis indicators. Generally, there are three types of diagnosis indicators. 


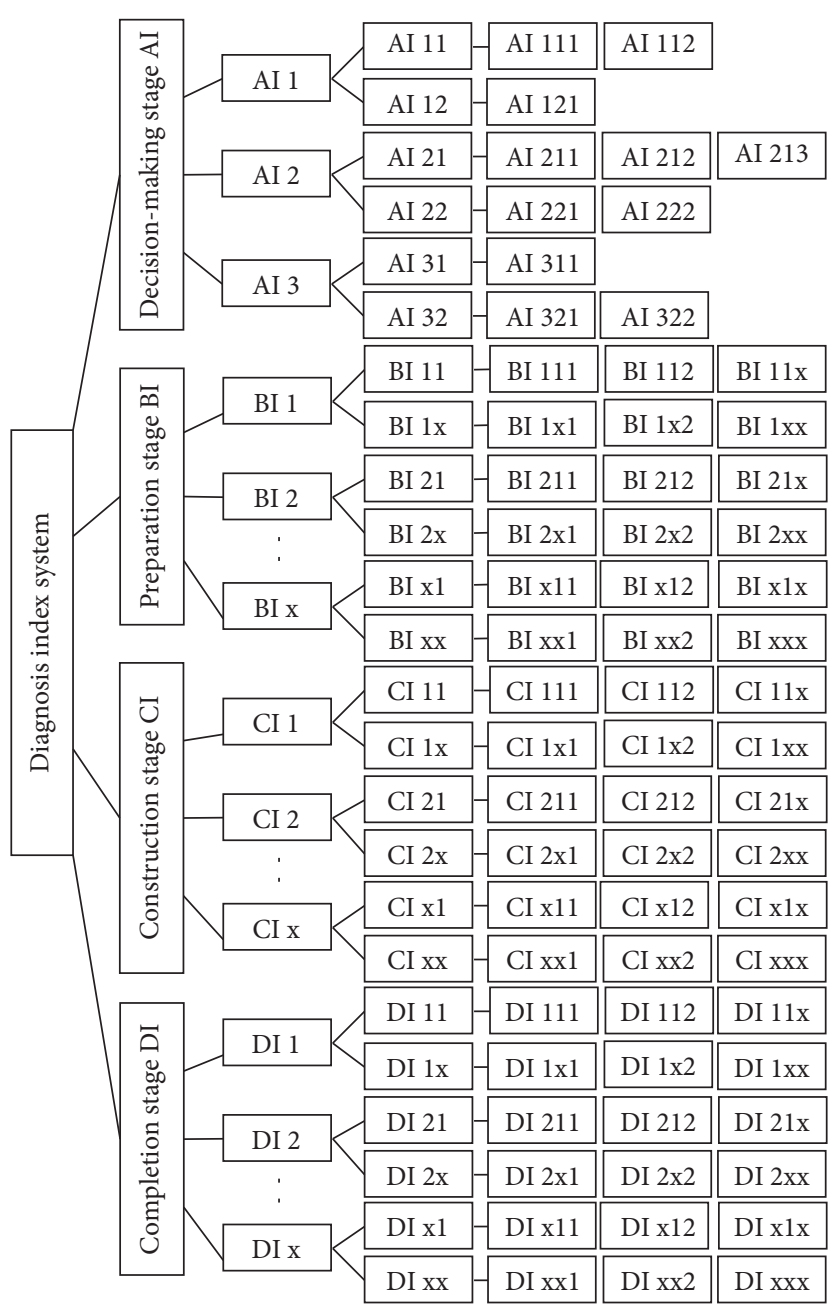

FiguRE 2: Diagnosis index system for implementation state of large-scale construction projects.

The first type is that which has clarified indicators. Taking the project quality as an example, the national standard named Unified Standards for Acceptance of Construction Quality has clear items about the assessment method as well as the specific parameters such as the dimensions, the flatness, the perpendicularity, and the mechanical mechanics' properties of the materials.

The second type is the indicators which have already been attached to the project, such as the project investment, the construction scale, the construction area, the completion time, and the concerned regulations that have been already made in advance. Once the project is carried out, the exact limitations will be applied to these indicators such as the money, the period, the materials, and the sites. Consequently, the corresponding indicators can be set up according to the exact limitations.

The third type is the indicators without specific and clear standards, such as the work efficiency of the staff and the coordination efficiency. Due to the diversity of the project, the management contents will be adjusted and revised according to varied project requirements. However, there are still two common characteristics for these indicators. First, these indicators are often determined in a qualitative or semiquantitative form. Second, although these indicators satisfy all the specific requirements and rules of an actual project, most contents of these indicators are still universal.

In practical engineering, to make full use of the established standards and regulations, the project managers often carry out the evaluation by means of giving an exact score to the implementation effect. This method has been widely used in practice and has received common acceptance. This kind of method provides a good reference for the indicator establishing in construction projects. To make this method not only satisfy all of the requirements of the projects but also practically applied in actual engineering, the detailed contents of the standards and rules are divided into different items which can be evaluated by varied scores. Consequently, the quantitative indicators are brought into the 
TABLE 4: Effectiveness comparison of the diagnosis index system.

\begin{tabular}{|c|c|c|c|c|c|c|c|c|c|c|c|c|}
\hline \multirow[b]{2}{*}{ Macrostate } & \multicolumn{8}{|c|}{ Medium state } & \multicolumn{4}{|c|}{ Microstate } \\
\hline & Diagnosis index & $T N$ & $R N$ & $\begin{array}{l}V R \\
\%\end{array}$ & $\begin{array}{l}\text { Diagnosis } \\
\text { index }\end{array}$ & $T N$ & $R N$ & $\begin{array}{l}V R \\
\%\end{array}$ & Diagnosis index & $T N$ & $R N$ & $\begin{array}{l}V R \\
\%\end{array}$ \\
\hline \multirow{10}{*}{$\begin{array}{l}\text { Decision-making } \\
\text { stage } \\
T N: 0.87 \\
R N: 0.81 \\
V R: 7.40\end{array}$} & \multirow[b]{2}{*}{ Project plan } & \multirow[b]{2}{*}{0.82} & \multirow[b]{2}{*}{0.77} & \multirow[b]{2}{*}{6.49} & \multirow{2}{*}{$\begin{array}{l}\text { Conception } \\
\quad \text { value } \\
\text { Suggestion } \\
\text { value }\end{array}$} & 0.77 & 0.72 & 6.94 & \multirow{2}{*}{$\begin{array}{l}\text { Information acquire rate } \\
\text { Improved rate } \\
\text { Work-efficiency ratio of } \\
\text { report }\end{array}$} & 0.85 & 0.80 & 6.25 \\
\hline & & & & & & 0.88 & 0.89 & 1.12 & & 0.88 & 0.89 & 1.12 \\
\hline & \multirow{5}{*}{ Feasible process } & \multirow{5}{*}{0.93} & \multirow{5}{*}{0.87} & \multirow{5}{*}{6.89} & \multirow{3}{*}{$\begin{array}{l}\text { Feasible } \\
\text { condition }\end{array}$} & \multirow{3}{*}{0.94} & \multirow{3}{*}{0.86} & \multirow{3}{*}{9.30} & \multirow{3}{*}{$\begin{array}{c}\text { Data reliable rate } \\
\text { Condition satisfied rate } \\
\text { Work-efficiency ratio of } \\
\text { report }\end{array}$} & 0.96 & 0.87 & 10.3 \\
\hline & & & & & & & & & & 0.92 & 0.83 & 10.8 \\
\hline & & & & & & & & & & 0.95 & 0.92 & 3.26 \\
\hline & & & & & \multirow{2}{*}{$\begin{array}{l}\text { Feasible } \\
\text { analysis }\end{array}$} & \multirow{2}{*}{0.93} & \multirow{2}{*}{0.89} & \multirow{2}{*}{4.49} & Method correctness rate & 0.96 & 0.95 & 1.05 \\
\hline & & & & & & & & & $\begin{array}{l}\text { Feasibility content } \\
\text { comprehensive rate }\end{array}$ & 0.89 & 0.82 & 8.53 \\
\hline & \multirow{3}{*}{$\begin{array}{c}\text { Decision for } \\
\text { approval }\end{array}$} & \multirow{3}{*}{0.86} & \multirow{3}{*}{0.79} & \multirow{3}{*}{8.86} & \multirow{3}{*}{$\begin{array}{l}\text { Project } \\
\text { decision } \\
\text { Project } \\
\text { approval }\end{array}$} & \multirow[t]{2}{*}{0.87} & \multirow[t]{2}{*}{0.80} & \multirow[t]{2}{*}{8.75} & $\begin{array}{c}\text { Work-efficiency ratio of } \\
\text { decision }\end{array}$ & 0.87 & 0.80 & 8.75 \\
\hline & & & & & & & & & Rule disobeying rate & 0.00 & 0.00 & 0.00 \\
\hline & & & & & & 0.85 & 0.77 & 10.4 & $\begin{array}{c}\text { Work-efficiency ratio of } \\
\text { approval }\end{array}$ & 0.85 & 0.77 & 10.4 \\
\hline
\end{tabular}

original qualitative management items, and all of the diagnosis indicators of the index system can be fully determined.

3.2.2. About Standardization of Indicators. During the assessment of the project implantation status, the analytical results obtained based on different standards include both qualitative indicators and quantitative indexes. Hence, the diagnosis results of the indexes are diversified. For the sake of the normalized evaluation, all of the diagnosis results need to be quantified. Generally, there are three types of diagnosis results, namely, the qualitative results, the quantitative results, and the semiquantitative results.

For the first type, the exact values can be obtained according to the national and departmental standards. For the second type, the detailed evaluation values can be obtained based on the difference comparison between the actual and the planned ones. For the third type, the evaluation values can be adaptively obtained based on the comparison between the standard ones and the diagnosis index values given by means of table indexes.

The other issue about the diagnosis standardization is caused due to the diversity of the diagnosis contents. Some of the diagnosis results may be a percentage value, some may be a binarization value which is either zero or one, and some may be numerical values. Therefore, the indicators need to be standardized as well when they are transformed into quantitative forms. In this paper, all of the indicator values are transformed into decimal forms which are in the range of $[0,1]$ based on the practical experiment experience and experts' professional suggestions.

3.2.3. About the Effect of Index System. In our method, the maximum error rates of the microstate, the median state, and the macrostate are $10.8 \%, 10.4 \%$, and $7.40 \%$, respectively, while the minimum error rates are pretty satisfied. More details about the results can be found in Table 4.
Obviously, the implementation state of the large-scale construction project can be finely diagnosed based on an exact quantitative index value. Other scholars have also presented other methods to deal with the implementation state diagnosis for large-scale constructions. For instance, Hou Xueliang et al. employed the Kernel Principal Component Analysis (KPCA) and Bayesian Inference to carry out the diagnosis on the construction quality [30, 31]. Comparatively, such a method is more suitable for the qualitative analysis on the implementation state, while our method is able to further obtain the exact index values and therefore seems more refined.

\section{Conclusions}

This paper proposed a new method to construct the diagnostic index system in large-scale construction projects and carries out the application of the proposed method into a case study for validation. The primary conclusions based on the study can be drawn up as follows:

(1) The establishing method of the index system for the construction projects is essential to the scientific management. However, the current frame of the index system is far from qualified in engineering applications, since the index system for different projects needs too many efforts to concretize and verify the indexes/indicators.

(2) How to scientifically pick the sensitive parameters to form the effective index system is the key point. Since the index parameters refer to many factors, it is significant to select the proper indicators in all-level stages. The Rough Set method based on the evidence theory is an effective approach to determine the appropriate indicators.

(3) It is shown that the diagnostic index system constructed by the proposed method is able to meet the actual management needs of large-scale construction 
projects, with qualified scientificity, systematicness, and completeness. Different from the index system constructed by other methods, the indexes/indicators established in this paper are more systematically correlated, with a better hierarchical progression in all levels of the index system.

Particularly, to solve the problem of the large number of indicators referring to the diversity of the diagnosis contents, the proposed method needs to transform the indicator values into the standardized decimal forms which are in the range of $[0,1]$. This procedure requests large amount of work and requires qualified experience of the operators. Therefore, there is a limitation of the proposed method which sometimes relies on the practical experiment experience and the experts' professional suggestions. In our next step work, we will carry out a specific study to improve this issue.

\section{Data Availability}

The data used to support the findings of this study are available from the corresponding author upon request.

\section{Conflicts of Interest}

The authors declare that there are no conflicts of interest regarding the publication of this paper.

\section{Acknowledgments}

This work was supported by the National Natural Science Foundation of China (71171081) and the Beijing Natural Science Foundation (9162014).

\section{References}

[1] J. Zhu, Z. Chen, and L.-j. Sun, "A method of construction of index system for highway maintenance management," Procedia - Social and Behavioral Sciences, vol. 96, pp. 1593-1602, 2013.

[2] A. H. Ibrahim and M. A. Shaker, "Sustainability index for highway construction projects," Alexandria Engineering Journal, vol. 58, no. 4, pp. 1399-1411, 2019.

[3] S. Hendiani and M. Bagherpour, "Developing an integrated index to assess social sustainability in construction industry using fuzzy logic," Journal of Cleaner Production, vol. 230, pp. 647-662, 2019.

[4] T. Zhao, Y. Jiang, H. Jiang et al., "Index system and methods for comprehensive assessment of cross-border power grid interconnection projects," Global Energy Interconnection, vol. 3, no. 6, pp. 532-544, 2020.

[5] A. Lalmi, G. Fernandes, and S. B. Souad, "A conceptual hybrid project management model for construction projects," Procedia Computer Science, vol. 181, pp. 921-930, 2021.

[6] Q. Gaosong and Y. Leping, "Measurement of internal audit effectiveness: construction of index system and empirical analysis," Microprocessors and Microsystems, vol. 21, p. 104046, 2021.

[7] Z. Dubský, L. Tichý, and D. Pavliňák, “A quantifiable approach to the selection of criteria and indexation for comparison of the gas pipeline projects leading to the EU: diversification rationality against securitisation?" Energy, vol. 225, Article ID 120238, 2021.

[8] I. Y. Wuni and G. Q. Shen, "Fuzzy modelling of the critical failure factors for modular integrated construction projects," Journal of Cleaner Production, vol. 264, Article ID 121595, 2020.

[9] Y. Elfahham, "Estimation and prediction of construction cost index using neural networks, time series, and regression," Alexandria Engineering Journal, vol. 58, no. 2, pp. 499-506, 2019.

[10] P. T. I. Lam, A. T. W. Yu, Z. Wu, and C. S. Poon, "Methodology for upstream estimation of construction waste for new building projects," Journal of Cleaner Production, vol. 230, pp. 1003-1012, 2019.

[11] M. Urbański, A. U. Haque, and I. Oino, “The moderating role of risk management in project planning and project success: evidence from construction businesses of Pakistan and the UK," Engineering Management in Production and Services, vol. 11, no. 1, pp. 23-35, 2019.

[12] O. Okudan, C. Budayan, and I. Dikmen, "A knowledge-based risk management tool for construction projects using casebased reasoning," Expert Systems with Applications, vol. 173, Article ID 114776, 2021.

[13] Y. Lu, P. Gong, Y. Tang, S. Sun, and Q. Li, “BIM-integrated construction safety risk assessment at the design stage of building projects," Automation in Construction, vol. 124, 2021.

[14] H. Zhou, Y. Zhao, Q. Shen, Y. Liu, and H. Cai, "Risk assessment and management via multi-source information fusion for undersea tunnel construction," Automation in Construction, vol. 111, 2020.

[15] G. Andrea Peñaloza, T. Abreu Saurin, and C. Torres Formoso, "Monitoring complexity and resilience in construction projects: the contribution of safety performance measurement systems," Applied Ergonomics, vol. 82, 2020.

[16] Q. Guo, S. Amin, H. Qianwen, and O. Haas, "Resilience assessment of safety system at subway construction sites applying analytic network process and extension cloud models," Reliability Engineering \& System Safety, vol. 201, 2020.

[17] U. H. Issa, S. A. A. Mosaad, and M. S. Hassan, "Evaluation and selection of construction projects based on risk analysis," Structures, vol. 27, pp. 361-370, 2020.

[18] H. O. Elhusseiny, I. Nosair, and A. S. Ezeldin, "Systematic processing framework for analyzing the factors of construction projects' delays in Egypt," Ain Shams Engineering Journal, vol. 13, 2021.

[19] J. Boon Hui Yap, P. L. Goay, Y. Bee Woon, and S. Martin, "Revisiting critical delay factors for construction: analysing projects in Malaysia," Alexandria Engineering Journal, vol. 60, no. 1, pp. 1717-1729, 2021.

[20] A. Adeboye Fashina, M. Abdillahi Omar, A. Abdullahi Sheikh, and F. F. Fakunle, "Exploring the significant factors that influence delays in construction projects in Hargeisa," Heliyon, vol. 7, no. 4, 2021.

[21] I. M. Mahdi, M. E. Ahmed, and R. Khallaf, "Decision support system for optimum soft clay improvement technique for highway construction projects," Ain Shams Engineering Journal, vol. 11, no. 1, pp. 213-223, 2020.

[22] M. Abdul Nabi, I. H. El-adaway, and C. Dagli, "A system dynamics model for construction safety behavior," Procedia Computer Science, vol. 168, pp. 249-256, 2020.

[23] A. Banakar, "Combined application of decision tree and fuzzy logic techniques for indexes," Journal of Process Engineering, vol. 40, no. 3, pp. 1212-1218, 2017. 
[24] K. Liu and Q. I. Song, "Application of index weighting system in large-scale construction project management," Architecture, Building Materials and Engineering Management, vol. 75, pp. 390-394, 2015.

[25] X. Hou and Y. Li, "Research on meticulous collection methods of construction information for engineering projects," in Proceedings of the 3rd International Conference on Engineering Technology and Application, pp. 321-326, Aizu-Wakamatsu Japan, November 2016.

[26] H. Qiao, "Evidence science from evidence based perspective," Evidence Science, vol. 21, no. 2, pp. 566-573, 2013.

[27] R.-l. Pan, L. Yuan-qin, and H.-l. Zhang, "Fuzzy-rough attribute redecution algorithm based on $\alpha$ information entropy," Control and Decision, vol. 32, no. 12, pp. 340-348, 2016, in Chinese.

[28] Z. Xu and Y. Hu, "The diagnosis of aero-engine's state based on rough set," in Proceedings of the 6th Workshop on Rough Set Theory, pp. 301-307, Santiago, Chile, December 2016.

[29] S. Hu and X. Xie, "Research on dynamic topological relationship between area and area based rought set," Journal of Henan Polytechnic University (Natural Science), vol. 34, no. 3, pp. 356-366, 2015, in Chinese.

[30] X. Hou, Method to Pick Management Index of Construction Project and its Application, China Electric Power Press, Beijing, China, 2014, in Chinese.

[31] X. Hou and Y. Wang, "On-line diagnosis model of construction project quality status and its simulation based on KPCA and bayesian inference," Journal of System \& Management, vol. 24, no. 4, pp. 472-479, 2015, in Chinese. 